\title{
HLA-B allele and haplotype diversity among Thai patients identified by PCR-SSOP: evidence for high risk of drug-induced hypersensitivity
}

\author{
Apichaya Puangpetch ${ }^{1,2}$, Napatrupron Koomdee ${ }^{1,2}$, Montri Chamnanphol, $^{1,2}$, \\ Thawinee Jantararoungtong ${ }^{1,2}$, Siwalee Santon ${ }^{1,2}$, Santirhat Prommas ${ }^{1,2}$, Yaowaluck Hongkaew ${ }^{1,2}$ \\ and Chonlaphat Sukasem ${ }^{1,2 *}$
}

\author{
Division of Pharmacogenomics and Personalized Medicine, Department of Pathology, Faculty of Medicine Ramathibodi Hospital, Mahidol University, Bangkok, \\ Thailand \\ ${ }^{2}$ Laboratory for Pharmacogenomics, Somdech Phra Debaratana Medical Center, Ramathibodi Hospital, Mahidol University, Bangkok, Thailand
}

\section{Edited by:}

Marcelo Rizzatti Luizon, University of California, San Francisco, USA

\section{Reviewed by:}

Wichittra Tassaneeyakul, Khon Kaen

University, Thailand

Melih O. Babaoglu, Hacettepe

University, Turkey

*Correspondence:

Chonlaphat Sukasem, Division of

Pharmacogenomics and

Personalized Medicine, Department of Pathology, Faculty of Medicine,

Ramathibodi Hospital, Mahidol University, Rama VI Road, Phaya Thai, Bangkok 10400, Thailand e-mail: chonlaphat.suk@ mahidol.ac.th
Background: There are 3 classes of HLA molecules; HLA class I, II and III, of which different classes have different functions. HLA-B gene which belongs to HLA class I play an important role predicting drug hypersensitivity.

Materials and Methods: Nine hundred and eighty-six Thai subjects who registered at a pharmacogenomics laboratory were determined for HLA-B genotype using a two-stage sequence-specific oligonucleotide probe system (PCR-SSOP).

Results: In this study, HLA-B alleles did not deviate from Hardy-Weinberg equilibrium $(P>$ 0.05). The most common $H L A-B$ alleles observed in this population were $H L A-B * 46: 01$ (11.51\%), HLA-B*58:01 (8.62\%), HLA-B*40:01 (8.22\%), HLA-B*15:02 (8.16\%) and $H L A-B^{*} 13: 01(6.95 \%)$. This finding revealed that $H L A-B$ allele frequency in the Thai population was consistent with the Chinese population $(p>0.05)$, however, differed from the Malaysian population $(p<0.05)$. The top five $H L A-B$ genotypes were HLA-B*40:01/46:01 (2.13\%), HLA-B*46:01/46:01 (2.03\%), HLA-B*40:01/58:01 (2.03\%), HLA-B*46:01/58:01 (1.93\%) and HLA-B*15:02/46:01 (1.83\%). This study found that $15.92 \%$ of Thai subjects carry $H L A-B^{*} 15: 02$, which has been associated with carbamazepine-induced severe cutaneous adverse drug reactions (SCARs). Moreover, $16.33 \%$ of Thai subjects carry the HLA-B*58:01 allele, which has been associated with allopurinol-induced SCARs.

Conclusion: This study demonstrates a high diversity of HLA-B polymorphisms in this Thai population. The high frequency of HLA-B pharmacogenomic markers in the population emphasizes the importance of such screening to predict/avoid drug hypersensitivity.

Keywords: HLA-B, pharmacogenomic markers, Thai, PCR-SSOP, SCARs, drug hypersensitivity

\section{INTRODUCTION}

Human leukocyte antigen (HLA) genes are located in the short arm of chromosome 6, are part of a large family of genes, and are inherited from both parents, one of paternal origin and one of maternal origin for each of the loci (Alper et al., 2006). HLA proteins are present at the cellular surface of antigen presenting cells. There are 3 classes of HLA. Class I loci (HLA$\mathrm{A},-\mathrm{B},-\mathrm{C})$ present endogenous antigens such as viral protein or tumor antigen to $\mathrm{CD} 8^{+} \mathrm{T}$ cells. Class II loci (HLA-DR, $\mathrm{DQ}$, -DP) present exogenous antigens to $\mathrm{CD} 4^{+} \mathrm{T}$ cells. Class III (Bf, C2, C4A) are involved in the complement system. HLA genes are highly polymorphic, which becomes important in associations of susceptibility or resistance to disease, development of tumor processes, molecular vaccine development (Dawson et al., 2001) and determination of organ or tissue transplant survival (Dhaliwal et al., 2003; Avila-Rios et al., 2009). In addition, $H L A$ allele frequency might be useful in anthropological studies.
Previous studies have reported HLA allele and haplotype frequencies of Thai populations. The most common HLA haplotypes were $A^{*} 33-C w^{*} 0302-B^{*} 5801-D R B^{*} 0301-D Q B 1^{*} 02(4.6 \%)$, $A^{*} 0207-C w^{*} 01-B^{*} 4601-D R B 1^{*} 09-D Q B 1^{*} 0303(3.4 \%)$ and $A^{*} 33-$ $C w^{*} 07$ (01-03)- $B^{*} 44-D R B 1^{*} 07-D Q B 1^{*} 02$ (2.6\%) (Kupatawintu et al., 2010; Romphruk et al., 2010).

$H L A-B$ alleles have been used as a marker for predicting druginduced adverse reactions (Sukasem et al., 2014a) and are a major contributor to hypersensitivity reactions involving direct stimulation of immune effector cells and imitating an allergic reaction. Several studies reported that allopurinol-induced severe cutaneous adverse reactions (SCARs) are strongly associated with the HLA-B* 58:01 allele in Han Chinese and Thais (Hung et al., 2005; Tassaneeyakul et al., 2009; Jantararoungtong et al., 2014). The $H L A-B^{*} 15: 02$ allele was strongly related to carbamazepine-induced Steven-Johnson syndrome (SJS)-toxic epidermal necrolysis (TEN) in Taiwanese and Thai populations 
(Tassaneeyakul et al., 2010; Chen et al., 2011; Sukasem et al., 2014b). Importantly, Thais showed cutaneous adverse reactions associated with $H L A-B^{*}$ 35:05 (Chantarangsu et al., 2009, 2011). In addition, the $H L A-B^{*} 57: 01$ allele is involved in abacavir-induced hypersensitivity reaction (Mallal et al., 2008). Consequently, screening of $H L A-B$ genotyping before prescription of medication may reduce the risk of SCARs and drug hypersensitivity reaction.

Presently, $H L A-B$ genotyping is available in clinical practices before commencing therapy with the aforementioned drugs in Thailand (Sukasem et al., 2014a). This study aimed to determine the distribution of $H L A-B$ haplotypes, and to establish the most common HLA haplotype-associated drug induced hypersensitivity using routine pharmacogenomic laboratory procedures. Over a period of 3 years, $H L A-B$ allele genotype was analyzed in 986 Thai people registered at the Laboratory for Pharmacogenomics, Ramathibodi Hospital, Thailand. The frequency of $H L A-B$ alleles and $H L A-B$ genotypes were determined and used to define the probability associated with a Pharmacogenomic marker indicating adverse drug reaction.

\section{MATERIALS AND METHODS SUBJECTS AND CHARACTERISTICS}

A descriptive, observational, cross-sectional, retrospective study was conducted in 986 unrelated individuals. Data were collected at the Laboratory for Pharmacogenomics, Somdech Phra Debaratana Medical Center (SDMC), Ramathibodi Hospital, Bangkok, Thailand during August 2011-June 2014. Among these patients, there were 590 (59.83\%) males and $396(40.17 \%)$ females. The mean age of patients at recruitment was $41.98 \pm 4.40$ years. The study was approved by the Ethics Committee of the Faculty of Medicine, Ramathibodi Hospital, Mahidol University. The protocol number is ID 04-56-24.

\section{GENOMIC DNA EXTRACTION}

Blood samples were collected into EDTA tubes. DNA was isolated using the MagNA Pure automated extraction system (Roche diagnostics, USA), which uses magnetic-bead technology with a lysis buffer and proteinase K. Nucleic acids bind to the surface of the magnetic glass particles. Cellular debris was removed by several washing steps and the purified nucleic acids were eluted. From the $1 \mathrm{ml}$ input volume of EDTA-whole blood, $200 \mu \mathrm{L}$ output volume of extracted genomic DNA product was obtained.

The quality of genomic DNA was assessed by using Nano Drop ND-1000. Genomic DNA was detected by measuring absorbance at $260 \mathrm{~nm}$. Purity of the sample was evaluated by calculation of the optical density (OD) ratio, 260/280 $\mathrm{nm}$. The recommended purified genomic DNA template for this study was $20 \mathrm{ng}$, and the OD ratio greater than 1.7. All DNA was aliquotted and stored at $-20^{\circ} \mathrm{C}$ before analysis.

\section{HLA-B TYPING}

$H L A-B$ genotyping was carried out using the Luminex ${ }^{\mathrm{TM}}$ Multiplex Technology (Luminex ${ }^{\circledR}$ IS 100, USA) based on Polymerase Chain Reaction-sequence specific oligonucleotides probe (PCR-SSOP) principles. Briefly, the PCR products were hybridized against a panel of oligonucleotide probes coated onto polystyrene microspheres. Probe sequences were complementary to stretches of polymorphic sequence within the target HLA$B$ alleles. The amplicon-probe complex was visualized using a colorimetric reaction and fluorescence detection technology. Data analyses for the HLA-B assays were performed with HLA fusion $^{\mathrm{TM}} 2.0$ software.

\section{STATISTICAL ANALYSIS}

The $H L A-B$ allele frequencies of the samples were assayed by direct counting and, subsequently, by dividing the total number of occurrences of that allele by the total number of alleles at that locus in the population. The samples were also evaluated for Hardy-Weinberg equilibrium using the Chi-square or Fisher's exact test if the number in any cell of the $2 \times 2$ contingency tables was less than five.

\section{RESULTS}

\section{HLA-B ALLELE FREQUENCY}

The study population comprised 986 samples which were obtained from Laboratory for Pharmacogenomics, Somdech Phra Debaratana Medical Center (SDMC), Ramathibodi Hospital, Thailand. The frequency of HLA-B alleles in 986 Thai patients is shown in Table 1. Overall, 116 different $H L A-B$ alleles were identified in this study, and $H L A-B^{*} 46: 01$ (11.51\%) was the predominant allele in this population. The most frequent alleles were $H L A-B^{*} 46: 01$ (11.51\%), HLA-B*58:01 (8.62\%), HLA$B^{*} 40: 01$ (8.22\%), HLA-B*15:02 (8.16\%), HLA-B*13:01 (6.95\%) and $H L A-B^{*} 44: 03(4.21 \%)$. The frequencies of $H L A-B$ alleles do not significantly deviate from Hardy-Weinberg equilibrium.

\section{FREQUENCY OF HLA-B GENOTYPE OCCURRENCE}

Overall, there were 448 different $H L A-B$ genotypes in the 986 Thai individuals analyzed. The most frequently observed

Table 1 | Identified $H L A-B$ allelic frequencies in Thai population ( $\mathbf{n}=\mathbf{9 8 6}$ ).

\begin{tabular}{lcccccc}
\hline Alleles & $\begin{array}{c}\text { No. of } \\
\text { alleles }\end{array}$ & $\begin{array}{c}\text { AF } \\
\text { (\%) }\end{array}$ & $\begin{array}{c}\text { Estimated } \\
\text { genotype }\end{array}$ & $\begin{array}{c}\text { No. of } \\
\text { genotypes }\end{array}$ & $\begin{array}{c}\text { Genotype } \\
\text { frequency (\%) }\end{array}$ & $\begin{array}{c}\text { HW } \\
\text { p-value }\end{array}$ \\
\hline$B^{*} 07: 02$ & 15 & 0.76 & 0.06 & 0 & 0.00 & 1 \\
$B^{*} 07: 05$ & 38 & 1.93 & 0.37 & 0 & 0.00 & 1 \\
$B^{*} 07: 13$ & 1 & 0.05 & 0.00 & 0 & 0.00 & 1 \\
$B^{*} 07: 14$ & 1 & 0.05 & 0.00 & 0 & 0.00 & 1 \\
$B^{*} 08: 01$ & 13 & 0.66 & 0.04 & 0 & 0.00 & 1 \\
$B^{*} 08: 02$ & 1 & 0.05 & 0.00 & 0 & 0.00 & 1 \\
$B^{*} 08: 03$ & 1 & 0.05 & 0.00 & 0 & 0.00 & 1 \\
$B^{*} 08: 12$ & 1 & 0.05 & 0.00 & 0 & 0.00 & 1 \\
$B^{*} 13: 01$ & 137 & 6.95 & 4.76 & 6 & 0.61 & 1 \\
$B^{*} 13: 02$ & 27 & 1.37 & 0.18 & 0 & 0.00 & 1 \\
$B^{*} 13: 03$ & 1 & 0.05 & 0.00 & 0 & 0.00 & 1 \\
$B^{*} 13: 39$ & 3 & 0.15 & 0.00 & 0 & 0.00 & 1 \\
$B^{*} 14: 13$ & 1 & 0.05 & 0.00 & 0 & 0.00 & 1 \\
$B^{*} 15: 01$ & 27 & 1.37 & 0.18 & 1 & 0.10 & 1 \\
$B^{*} 15: 02$ & 161 & 8.16 & 6.57 & 8 & 0.81 & 1 \\
$B^{*} 15: 04$ & 4 & 0.20 & 0.00 & 0 & 0.00 & 1 \\
\hline & & & & & & (Continued)
\end{tabular}


Table 1 | Continued

\begin{tabular}{|c|c|c|c|c|c|c|}
\hline Alleles & $\begin{array}{l}\text { No. of } \\
\text { alleles }\end{array}$ & $\begin{array}{l}\text { AF } \\
(\%)\end{array}$ & $\begin{array}{c}\text { Estimated } \\
\text { genotype }\end{array}$ & $\begin{array}{c}\text { No. of } \\
\text { genotypes }\end{array}$ & $\begin{array}{c}\text { Genotype } \\
\text { frequency }(\%)\end{array}$ & $\begin{array}{c}\text { HW } \\
p \text {-value }\end{array}$ \\
\hline$B^{*} 15: 06$ & 1 & 0.05 & 0.00 & 0 & 0.00 & 1 \\
\hline$B^{*} 15: 07$ & 3 & 0.15 & 0.00 & 0 & 0.00 & 1 \\
\hline$B^{*} 15: 11$ & 5 & 0.25 & 0.01 & 0 & 0.00 & 1 \\
\hline$B^{*} 15: 12$ & 12 & 0.61 & 0.04 & 0 & 0.00 & 1 \\
\hline$B^{*} 15: 13$ & 11 & 0.56 & 0.03 & 0 & 0.00 & 1 \\
\hline$B^{*} 15: 17$ & 4 & 0.20 & 0.00 & 0 & 0.00 & 1 \\
\hline$B^{*} 15: 18$ & 3 & 0.15 & 0.00 & 0 & 0.00 & 1 \\
\hline$B^{*} 15: 20$ & 2 & 0.10 & 0.00 & 0 & 0.00 & 1 \\
\hline$B^{*} 15: 21$ & 3 & 0.15 & 0.00 & 0 & 0.00 & 1 \\
\hline$B^{*} 15: 22$ & 1 & 0.05 & 0.00 & 0 & 0.00 & 1 \\
\hline$B^{*} 15: 25$ & 28 & 1.42 & 0.20 & 0 & 0.00 & 1 \\
\hline$B^{*} 15: 27$ & 2 & 0.10 & 0.00 & 0 & 0.00 & 1 \\
\hline$B^{*} 15: 31$ & 4 & 0.20 & 0.00 & 0 & 0.00 & 1 \\
\hline$B^{*} 15: 32$ & 7 & 0.35 & 0.01 & 0 & 0.00 & 1 \\
\hline$B^{*} 15: 35$ & 17 & 0.86 & 0.07 & 1 & 0.10 & 1 \\
\hline$B^{*} 15: 88$ & 1 & 0.05 & 0.00 & 0 & 0.00 & 1 \\
\hline$B^{*} 18: 01$ & 63 & 3.19 & 1.01 & 0 & 0.00 & 1 \\
\hline$B^{*} 18: 01$ & 1 & 0.05 & 0.00 & 0 & 0.00 & 1 \\
\hline$B^{*} 18: 02$ & 45 & 2.28 & 0.51 & 0 & 0.00 & 1 \\
\hline$B^{*} 18: 02$ & 1 & 0.05 & 0.00 & 0 & 0.00 & 1 \\
\hline$B^{*} 18: 09$ & 1 & 0.05 & 0.00 & 0 & 0.00 & 1 \\
\hline$B^{*} 18: 18$ & 1 & 0.05 & 0.00 & 0 & 0.00 & 1 \\
\hline$B^{*} 27: 03$ & 3 & 0.15 & 0.00 & 0 & 0.00 & 1 \\
\hline$B^{*} 27: 04$ & 32 & 1.62 & 0.26 & 0 & 0.00 & 1 \\
\hline$B^{*} 27: 06$ & 18 & 0.91 & 0.08 & 0 & 0.00 & 1 \\
\hline$B^{*} 27: 61$ & 10 & 0.51 & 0.03 & 0 & 0.00 & 1 \\
\hline$B^{*} 27: 86$ & 1 & 0.05 & 0.00 & 0 & 0.00 & 1 \\
\hline$B^{*} 35: 01$ & 29 & 1.47 & 0.21 & 0 & 0.00 & 1 \\
\hline$B^{*} 35: 02$ & 2 & 0.10 & 0.00 & 0 & 0.00 & 1 \\
\hline$B * 35: 03$ & 17 & 0.86 & 0.07 & 0 & 0.00 & 1 \\
\hline$B^{*} 35: 05$ & 40 & 2.03 & 0.41 & 1 & 0.10 & 1 \\
\hline$B^{*} 35: 08$ & 1 & 0.05 & 0.00 & 0 & 0.00 & 1 \\
\hline$B^{*} 35: 11$ & 1 & 0.05 & 0.00 & 0 & 0.00 & 1 \\
\hline$B^{*} 35: 13$ & 1 & 0.05 & 0.00 & 0 & 0.00 & 1 \\
\hline$B * 35: 20$ & 1 & 0.05 & 0.00 & 0 & 0.00 & 1 \\
\hline$B^{*} 35: 23$ & 1 & 0.05 & 0.00 & 0 & 0.00 & 1 \\
\hline$B^{*} 35: 58$ & 1 & 0.05 & 0.00 & 0 & 0.00 & 1 \\
\hline$B^{*} 35: 68$ & 2 & 0.10 & 0.00 & 0 & 0.00 & 1 \\
\hline$B^{*} 37: 01$ & 8 & 0.41 & 0.02 & 0 & 0.00 & 1 \\
\hline$B^{*} 38: 01$ & 2 & 0.10 & 0.00 & 0 & 0.00 & 1 \\
\hline$B^{*} 38: 02$ & 61 & 3.09 & 0.94 & 3 & 0.30 & 0.624 \\
\hline$B^{*} 38: 17$ & 1 & 0.05 & 0.00 & 0 & 0.00 & 1 \\
\hline$B^{*} 38: 22$ & 1 & 0.05 & 0.00 & 0 & 0.00 & 1 \\
\hline$B^{*} 38: 23$ & 2 & 0.10 & 0.00 & 0 & 0.00 & 1 \\
\hline$B^{*} 39: 01$ & 14 & 0.71 & 0.05 & 0 & 0.00 & 1 \\
\hline$B^{*} 39: 09$ & 18 & 0.91 & 0.08 & 0 & 0.00 & 1 \\
\hline$B^{*} 39: 15$ & 13 & 0.66 & 0.04 & 0 & 0.00 & 1 \\
\hline$B^{*} 39: 24$ & 5 & 0.25 & 0.01 & 0 & 0.00 & 1 \\
\hline$B^{*} 40: 01$ & 162 & 8.22 & 6.65 & 6 & 0.61 & 1 \\
\hline$B^{*} 40: 02$ & 30 & 1.52 & 0.23 & 0 & 0.00 & 1 \\
\hline$B^{*} 40: 03$ & 1 & 0.05 & 0.00 & 0 & 0.00 & 1 \\
\hline
\end{tabular}

(Continued)
Table 1 | Continued

Alleles No. of AF Estimated No. of Genotype HW alleles $(\%)$ genotype genotypes frequency $(\%) p$-value

\begin{tabular}{lcccccc}
\hline$B^{*} 40: 04$ & 7 & 0.35 & 0.01 & 0 & 0.00 & 1 \\
$B^{*} 40: 06$ & 14 & 0.71 & 0.05 & 1 & 0.10 & 1 \\
$B^{*} 40: 09$ & 1 & 0.05 & 0.00 & 0 & 0.00 & 1 \\
$B^{*} 40: 10$ & 6 & 0.30 & 0.01 & 0 & 0.00 & 1 \\
$B^{*} 40: 23$ & 1 & 0.05 & 0.00 & 0 & 0.00 & 1 \\
$B^{*} 40: 59$ & 1 & 0.05 & 0.00 & 0 & 0.00 & 1 \\
$B^{*} 41: 01$ & 1 & 0.05 & 0.00 & 0 & 0.00 & 1 \\
$B^{*} 41: 10$ & 1 & 0.05 & 0.00 & 0 & 0.00 & 1 \\
$B^{*} 44: 01$ & 2 & 0.10 & 0.00 & 0 & 0.00 & 1 \\
$B^{*} 44: 02$ & 14 & 0.71 & 0.05 & 0 & 0.00 & 1 \\
$B^{*} 44: 02$ & 1 & 0.05 & 0.00 & 0 & 0.00 & 1 \\
$B^{*} 44: 03$ & 83 & 4.21 & 1.75 & 1 & 0.10 & 1 \\
$B^{*} 44: 54$ & 1 & 0.05 & 0.00 & 0 & 0.00 & 1 \\
$B^{*} 46: 01$ & 227 & 11.51 & 13.07 & 20 & 2.03 & 0.292
\end{tabular}

0.10

$\begin{array}{llll}B * 46: 12 & 26 & 1.32 & 0.17\end{array}$

$B^{*} 46: 16 \quad 1 \quad 0.05 \quad 0.00$

$B^{*} 48: 01 \quad 9 \quad 0.46 \quad 0.02$

$B^{*} 48: 03 \quad 7 \quad 0.35 \quad 0.01$

$\begin{array}{llll}B * 48: 21 & 1 & 0.05 & 0.00\end{array}$

$\begin{array}{llll}B^{*} 50: 01 & 11 & 0.56 & 0.03\end{array}$

$\begin{array}{llll}B * 51: 01 & 65 & 3.30 & 1.07\end{array}$

$\begin{array}{llll}B^{*} 51: 02 & 16 & 0.81 & 0.06\end{array}$

$\begin{array}{llll}B * 51: 04 & 4 & 0.20 & 0.00\end{array}$

$\begin{array}{llll}B * 51: 06 & 3 & 0.15 & 0.00\end{array}$

$\begin{array}{llll}B * 51: 07 & 1 & 0.05 & 0.00\end{array}$

$\begin{array}{llll}B^{*} 51: 43 & 1 & 0.05 & 0.00\end{array}$

$\begin{array}{llll}B * 51: 45 & 1 & 0.05 & 0.00\end{array}$

$\begin{array}{llll}B * 52: 01 & 43 & 2.18 & 0.47\end{array}$

$\begin{array}{llll}B^{*} 52: 07 & 1 & 0.05 & 0.00\end{array}$

$\begin{array}{llll}B * 53: 17 & 5 & 0.25 & 0.01\end{array}$

$\begin{array}{llll}B * 54: 01 & 21 & 1.06 & 0.11\end{array}$

$\begin{array}{llll}B^{*} 54: 01 & 2 & 0.10 & 0.00\end{array}$

$\begin{array}{llll}B^{*} 54: 04 & 1 & 0.05 & 0.00\end{array}$

$\begin{array}{llll}B^{*} 54: 16 & 1 & 0.05 & 0.00\end{array}$

$\begin{array}{llll}B^{*} 55: 01 & 8 & 0.41 & 0.02\end{array}$

$\begin{array}{llll}B^{*} 55: 02 & 23 & 1.17 & 0.13\end{array}$

$\begin{array}{llll}B * 55: 03 & 1 & 0.05 & 0.00\end{array}$

$\begin{array}{llll}B * 55: 04 & 2 & 0.10 & 0.00\end{array}$

$\begin{array}{llll}B^{*} 55: 10 & 1 & 0.05 & 0.00\end{array}$

$\begin{array}{llll}B^{*} 55: 44 & 2 & 0.10 & 0.00\end{array}$

$\begin{array}{llll}B^{*} 56: 01 & 15 & 0.76 & 0.06\end{array}$

0.00

0.00

0.00

0.00

0.00

0.00

0.00

0.00

0.00

0.00

0.00

0.00

0.00

0.00

0.00

0.00

0.00

0.00

0.00

0.00

0.00

0.00

0.00

0.00

0.00

0.00

0.00

$\begin{array}{llll}B * 56: 02 & 1 & 0.05 & 0.00\end{array}$

0.00

$\begin{array}{llll}B * 56: 04 & 6 & 0.30 & 0.01\end{array}$

$\begin{array}{llll}B^{*} 56: 16 & 3 & 0.15 & 0.00\end{array}$

0.00

0.00

$\begin{array}{llll}B * 57: 01 & 30 & 1.52 & 0.23\end{array}$

0.00

$\begin{array}{llll}B * 57: 21 & 2 & 0.10 & 0.00\end{array}$

0.00

0.91

$\begin{array}{lccc}B^{*} 58: 01 & 170 & 8.62 & 7.33 \\ B^{*} 58.34 & 1 & 0.05 & 0.00\end{array}$

0.00

1

Total $1972 \quad 100$ 
Table 2 | Top 10 common genotypes in the Thais $(n=986)$.

\begin{tabular}{lcc}
\hline Genotypes & No. of subjects & Frequency (\%) \\
\hline$B^{*} 40: 01 / 46: 01$ & 21 & 2.13 \\
$B^{*} 46: 01 / 46: 01$ & 20 & 2.03 \\
$B^{*} 40: 01 / 58: 01$ & 20 & 2.03 \\
$B^{*} 46: 01 / 58: 01$ & 19 & 1.93 \\
$B^{*} 15: 02 / 46: 01$ & 18 & 1.83 \\
$B^{*} 15: 02 / 40: 01$ & 15 & 1.52 \\
$B^{*} 13: 01 / 58: 01$ & 13 & 1.32 \\
$B^{*} 13: 01 / 15: 02$ & 12 & 1.22 \\
$B^{*} 13: 01 / 46: 01$ & 11 & 1.12 \\
$B^{*} 38: 02 / 46: 01$ & 11 & 1.12 \\
$B^{*} 15: 02 / 44: 03$ & 11 & 1.12 \\
$B^{*} 13: 01 / 40: 01$ & 10 & 1.01 \\
\hline
\end{tabular}

HLA-B genotype was $H L A-B^{*} 40: 01 / 46: 01$. The 10 most common genotype frequencies in this Thai population were HLA-B* 40:01/46:01 (2.13\%), HLA-B*46:01/46:01 (2.03\%), HLA$B^{*} 40: 01 / 58: 01$ (2.03\%), HLA-B*46:01/58:01 (1.93\%), HLA-B 15:02/46:01 (1.83\%), HLA-B*15:02/40:01 (1.52\%), HLA-B* 13:01/58:01 (1.32\%), HLA-B*13:01/15:02 (1.22\%), HLA-B* 13:01/46:01 (1.12\%), HLA-B*38:02/46:01 (1.12\%), HLA-B* 15:02/44:03 (1.12\%), and $H L A-B^{*} 13: 01 / 40: 01$ (1.01\%). None of these genotypes were present in more than $5 \%$ of the population. Table 2 shows the frequency of the top 10 genotypes the Thai population in this study.

\section{FREQUENCY OF THE STRONG PREDICTION OF HLA-B PHARMACOGENOMICS MARKERS IN THAI POPULATION}

With regard to $H L A-B$ pharmacogenomic markers in the Thai population, high frequencies of $H L A-B^{*} 58: 01$ (16.33\%) were observed, followed by HLA-B*15:02 (15.92\%), HLA-B* 35:05 $(4.36 \%)$, and $H L A-B^{*} 57: 01$ (3.04\%). Table 3 shows the frequencies of the genotypes of $H L A-B$ pharmacogenomic markers in this Thai population. Of the 986 subjects who were included in the study, 161 subjects $(16.43 \%)$ were found to carry the $H L A-B^{*}$ 58:01 allele. One hundred and fifty-two subjects carry the heterozygous $H L A-B^{*} 58: 01$ genotype and 9 subjects carry the homozygous $H L A-B^{*}$ 58:01 genotype. Among these, 56.02\% were males and $43.98 \%$ were female.

$H L A-B^{*} 15: 02$ is a genetic marker previously related to induction of SJS/TEN in carbamazepine treated patients. One hundred and fifty-seven subjects $(15.92 \%)$ were found to carry $H L A-B^{\star} 15: 02 ; 151$ subjects $(15.31 \%)$ were heterozygous for the $H L A-B^{*} 15: 02$ allele and 8 subjects $(0.81 \%)$ carry homozygous $H L A-B^{*} 15: 02$. Males accounted for $60.23 \%$ and females $39.77 \%$. In addition, $H L A-B^{*}$ 15:02 belong to the HLA-B75 family, which consists of $H L A-B^{*} 15: 08, H L A-B^{*} 15: 11, H L A-B^{*} 15: 18$ and HLA$B^{*} 15: 21$, and is associated with carbamazepine-induced SJS/TEN. Five subjects with $H L A-B^{*} 15: 11$ heterozygous genotype and 3 subjects with $H L A-B^{*} 15: 18, H L A-B^{*} 15: 21$ heterozygous genotype were found, whereas $H L A-B^{*} 15: 08$ was not found in either heterozygous and homozygous genotypes in this population.

Likewise, the HLA-B*3505 allele was associated with nevirapine-induced hypersensitivity reactions in HIV-infected Thai patients. Forty-three subjects $(4.36 \%)$ carried the
$H L A-B^{*}$ 35:05 allele, one subject and 42 subjects (4.26\%) carry homozygous and heterozygous $H L A-B^{*}$ 35:05 genotypes, respectively, Thirty subjects $(3.04 \%)$ carry heterozygous HLA$B^{*}$ 57:01, which is known to be associated with abacavir-induced hypersensitivity syndrome (AHS). No homozygous $H L A-B^{*}$ 57:01 genotype was identified in this study.

\section{DISCUSSION}

The HLA-B allele frequencies of 968 Thai subjects were investigated. This is the first report of $H L A-B$ genotyping in the Thai population using the Luminex HLA-SSOP method. Our data showed that the Thai population has extensive diversity at the $H L A-B$ locus. One hundred and sixteen allele types were identified and the frequencies of $H L A-B$ alleles did not significantly deviate from Hardy-Weinberg equilibrium. The top five alleles with frequencies over $5 \%$ include $H L A$ $B^{*} 46: 01$ (11.51\%), HLA-B*58:01 (8.62\%), HLA-B*40:01 (8.22\%), $H L A-B^{*} 15: 02(8.16 \%)$, and $H L A-B^{*} 13: 01$ (6.95\%). These frequencies were similar to those observed in the Singaporean Chinese: HLA-B $B^{*} 40: 01$ (17.2\%), HLA-B $B^{*} 46: 01$ (13.2\%), HLA$B^{*}$ 58:01 (10.4\%), HLA-B*13:01 (8.40\%), HLA-B*15:02 (5.70\%) and Hong Kong Chinese: HLA-B*46:01 (16.3\%), HLA-B*40:01 (15.2\%), HLA-B* 58:01 (7.30\%), HLA-B* 15:02 (10.2\%) and HLA$B^{*} 13: 01$ (7.80\%) (Williams et al., 2001; Middleton et al., 2004). These data differed, however, from the Jehai population in Malaysia nearest the south of Thailand: $H L A-B^{*} 46: 01$ (2\%), HLA$B^{*}$ 58:01 (6\%), HLA-B*40:01 (2\%), HLA-B*15:02 (2\%), HLA$B^{*} 13: 01$ (8\%) (Jinam et al., 2010; Kupatawintu et al., 2010; Romphruk et al., 2010). This may indicate that Thais have a closer relationship with their Chinese neighbors than with Malaysia. Previous studies of HLA alleles in the Thai population had larger subject numbers, but reported no pharmacogenomic data, which we present in the current study. $H L A-B^{*}$ 15:02 allele is found in high prevalence among people in South-East Asian countries. The frequency of the $H L A-B$ allele varies among different populations suggesting that different alleles may also function in drug hypersensitivity. Currently, there has been an increase of publications associated with $H L A-B$ alleles and drug hypersensitivity (Sukasem et al., 2014a).

In our study, $15.92 \%(n=157)$ of Thai subjects carry HLA$B^{*}$ 15:02 genotype, which has been associated with severe adverse drug reaction in response to carbamazepine during epileptic treatment (Tassaneeyakul et al., 2010; Kulkantrakorn et al., 2012; Tangamornsuksan et al., 2013) or other aromatic amine anticonvulsants such as oxcarbazepine, phenytoin, and lamotrigine (Man et al., 2007; Hung et al., 2010; Koomdee et al., 2014). Further, the serotype HLA-B75 family, such as $H L A-B^{*} 15: 08$, $H L A-B^{*} 15: 11(0.25 \%, n=5), H L A-B^{*} 15: 18(0.15 \%, n=3)$ and $H L A-B^{*} 15: 21(0.15 \%, n=3)$, is associated with carbamazepineinduced SJS/TEN (Daly and Day, 2009; Lin et al., 2009). In this study, 168 subjects (17.03\%) carrying members of serotype HLAB75 family alleles may be susceptible to carbamazepine-induced SIS/TEN.

The genetic predisposition to nevirapine and abacavirinduced hypersensitivity reaction (HSR) has been reported for $H L A-B^{*}$ 35:05 and HLA-B* 57:01 alleles, respectively (Mallal et al., 2008; Chantarangsu et al., 2009, 2011). The data showed that $4.36 \%$ of Thai people carry the $H L A-B^{\star} 35: 05$ genotype and 3.04\% 
Table 3 | Pharmacogenomics markers of HLA-B genotype in a Thai population $(n=986)$.

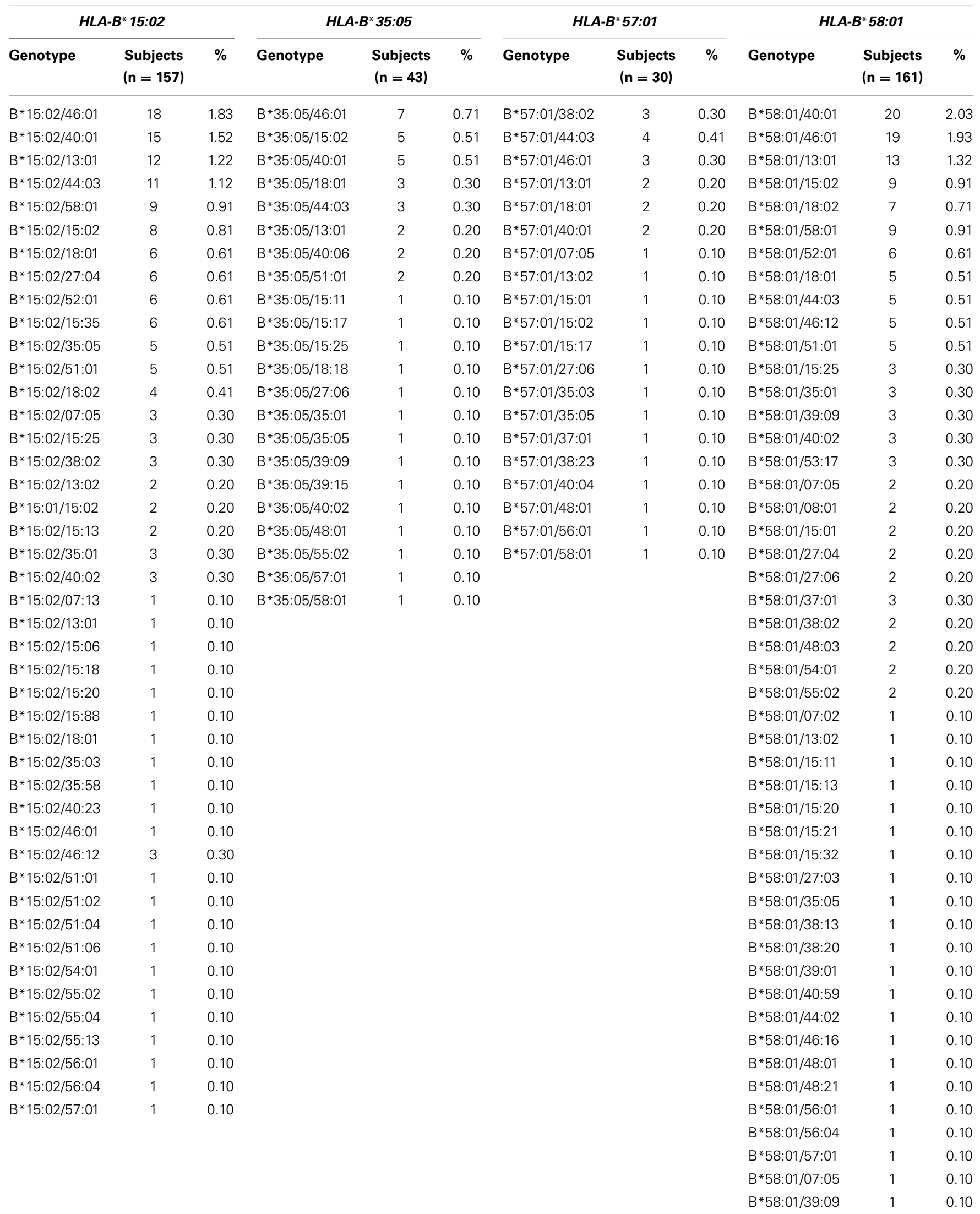




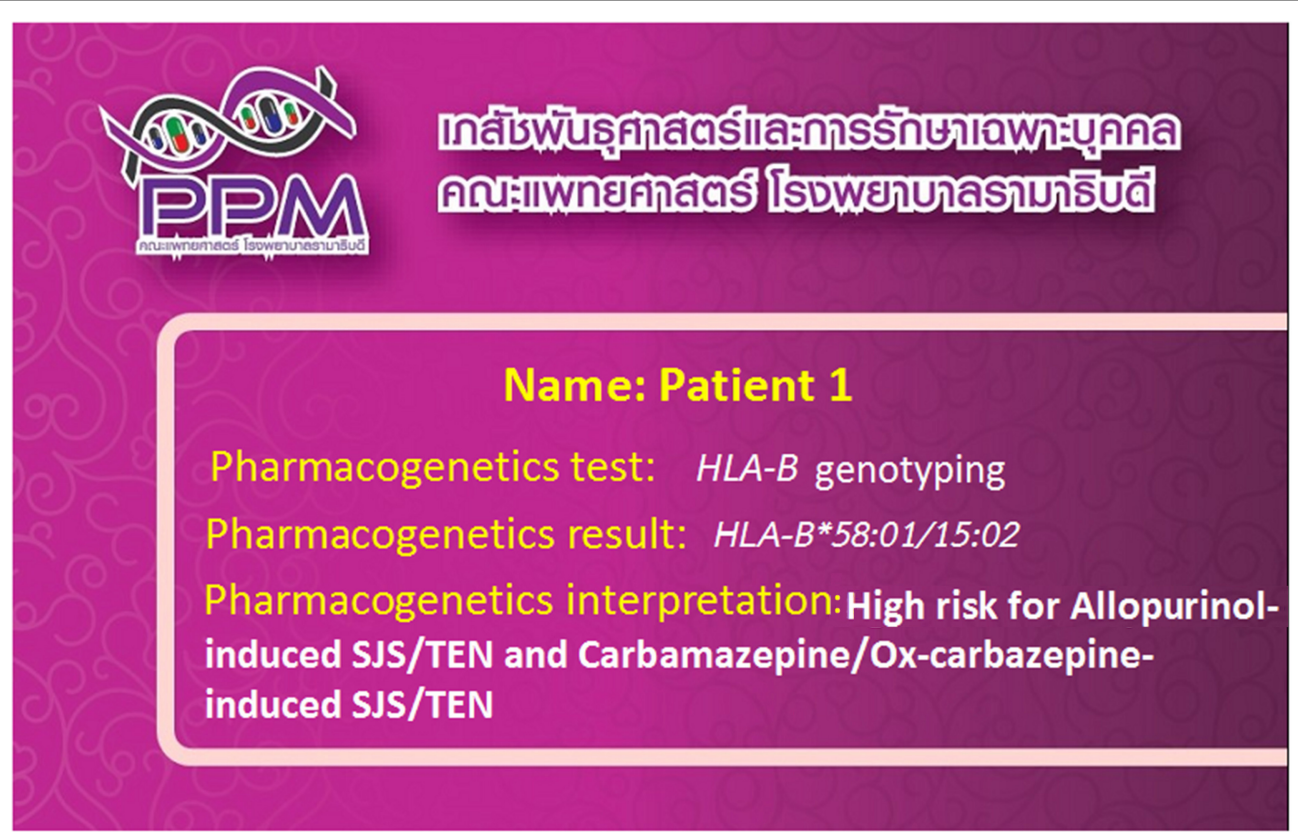

FIGURE 1 | "Pharmacogenomics cards" have been successfully implemented in clinical practice in Thailand. The patients are tested for the HLA-B alleles which are associated with the ADRs related with the use of concerned drugs.

carry the HLA-B*57:01 genotype (Chantarangsu et al., 2009). Furthermore, HLA allotypes closely related to abacavir response are $H L A-B^{*}$ 57:03, $H L A-B^{*} 57: 02$, and $H L A-B^{*} 58: 01$ (Illing et al., 2012). Consequently, $23.73 \%$ of Thai people might be at risk of drug hypersensitivity from nevirapine or abacavir treatment.

In the present study, we found that $16.33 \%$ of Thai people carry the $H L A-B^{*}$ 58:01 allele, which is associated with allopurinol hypersensitivity in gout treatment (Tassaneeyakul et al., 2009; Saokaew et al., 2014). Beside drug hypersensitivity, other studies of $H L A-B$ alleles, such as $H L A-B^{*} 46: 01$, report a significant increase in severity of cerebral malaria compared with patients with mild CNS symptoms (Hirayama et al., 1998). Moreover, $H L A-B^{*}$ 40:01 is associated with lipodystrophy in Thai HIV-1positive patients who received antiretroviral therapy containg stavudine (Wangsomboonsiri et al., 2010). HLA-B* 13:01 has been suggested as a genetic marker for dermal hypersensitivity associated with Trichloroethylene, an industrial solvent (Li et al., 2007).

Our findings demonstrated the diversity of $H L A-B$ alleles in the Thai population, and many more HLA associated with ADR. Other classes of HLA may be observed in upcoming studies. The subjects enrolled in the study were mostly from central Thailand. This narrow sample may restrict our calculations of HLA-B allele distribution in Thai populations. Future studies should consider this limitation of our survey.

$H L A$-associated drug hypersensitivity is dependent upon the different populations studied, and variation in genetic backgrounds. Recently, HLA-B genotyping has become accessible in clinical practice, providing appropriate clinical monitoring, patient counseling and recommendations for treatment. Interestingly, "pharmacogenetic tests" and "pharmacogenomic cards" (Figure 1) have been successfully implemented in clinical practice in Thailand at the Laboratory for Pharmacogenomics, Somdech Phra Debaratana Medical Center, Ramathibodi Hospital (Sukasem et al., 2014a). Recently, HLA-B* 15:02 screening has been preliminarily introduced by the National Health Security Office (NHSO), Thailand, to screen patients who may be at risk of carbamazepine-induced SJS/TEN.

In conclusion, our data suggest that $H L A-B$ genotype should be screened before medication is prescribed to reduce the incidence of drug hypersensitivity. These findings provided useful information in the study of pharmacogenomics and HLA-B polymorphisms in the Thai population. The frequency of the HLA-B alleles associated with drug hypersensitivity will help in designing alternative treatment regimens or better therapy for affected individuals. Understanding of the mechanism underlying drug hypersensitivity reactions requires further investigation.

\section{ACKNOWLEDGMENTS}

This study was supported by grants from the (1) Khun Poom Foundation, The Project of Her Royal Highness Princess Ubonratana Rajakanya Siriwatana Bhanawadee, (2) Pharmacogenomics for Autistic Children, Office of National Research Council of Thailand (3) Faculty of Medicine, Ramathibodi Hospital, Mahidol University (4) Pharmacogenomics Project under Thailand Center of Excellence in Life Sciences.

\section{REFERENCES}

Alper, C. A., Larsen, C. E., Dubey, D. P., Awdeh, Z. L., Fici, D. A., and Yunis, E. J. (2006). The haplotype structure of the human major histocompatibility complex. Hum. Immunol. 67, 73-84. doi: 10.1016/j.humimm.2005.11.006 Avila-Rios, S., Ormsby, C. E., Carlson, J. M., Valenzuela-Ponce, H., Blanco-Heredia, J., Garrido-Rodriguez, D., et al. (2009). Unique features of HLA-mediated HIV 
evolution in a Mexican cohort: a comparative study. Retrovirology 6:72. doi: $10.1186 / 1742-4690-6-72$

Chantarangsu, S., Mushiroda, T., Mahasirimongkol, S., Kiertiburanakul, S., Sungkanuparph, S., Manosuthi, W., et al. (2009). HLA-B*3505 allele is a strong predictor for nevirapine-induced skin adverse drug reactions in HIV-infected Thai patients. Pharmacogenet. Genomics 19, 139-146. doi: 10.1097/FPC.0b013e32831d0faf

Chantarangsu, S., Mushiroda, T., Mahasirimongkol, S., Kiertiburanakul, S., Sungkanuparph, S., Manosuthi, W., et al. (2011). Genome-wide association study identifies variations in 6p21.3 associated with nevirapine-induced rash. Clin. Infect. Dis. 53, 341-348. doi: 10.1093/cid/cir403

Chen, P., Lin, J. J., Lu, C. S., Ong, C. T., Hsieh, P. F., Yang, C. C., et al. (2011). Carbamazepine-induced toxic effects and HLA-B* 1502 screening in Taiwan. N. Engl. J. Med. 364, 1126-1133. doi: 10.1056/NEJMoa1009717

Daly, A. K., and Day, C. P. (2009). Genetic association studies in drug-induced liver injury. Semin. Liver Dis. 29, 400-411. doi: 10.1055/s-0029-1240009

Dawson, D. V., Ozgur, M., Sari, K., Ghanayem, M., and Kostyu, D. D. (2001). Ramifications of HLA class I polymorphism and population genetics for vaccine development. Genet. Epidemiol. 20, 87-106. doi: 10.1002/10982272(200101)20:1<87::AID-GEPI8 > 3.0.CO;2-R

Dhaliwal, J. S., Too, C. L., Lisut, M., Lee, Y. Y., and Murad, S. (2003). HLA-B27 polymorphism in the Malays. Tissue Antigens 62, 330-332. doi: 10.1034/j.13990039.2003.00107.x

Hirayama, K., Kikuchi, M., Oumaporn, T., Yupaporn, W., Na-Bangchang, K., Karbwang, J., et al. (1998). HLA-B* 4601 Increased in the adult patients with severe malaria at mae sod hospital in Thailand. Tokai J. Exp. Clin. Med. 23, $81-83$.

Hung, S. I., Chung, W. H., Liou, L. B., Chu, C. C., Lin, M., Huang, H. P., et al. (2005). HLA-B*5801 allele as a genetic marker for severe cutaneous adverse reactions caused by allopurinol. Proc. Natl. Acad. Sci. U.S.A. 102, 4134-4139. doi: 10.1073/pnas.0409500102

Hung, S. I., Chung, W. H., Liu, Z. S., Chen, C. H., Hsih, M. S., Hui, R. C., et al. (2010). Common risk allele in aromatic antiepileptic-drug induced Stevens-Johnson syndrome and toxic epidermal necrolysis in Han Chinese. Pharmacogenomics 11, 349-356. doi: 10.2217/pgs.09.162

Illing, P. T., Vivian, J. P., Dudek, N. L., Kostenko, L., Chen, Z., Bharadwaj, M., et al. (2012). Immune self-reactivity triggered by drug-modified HLA-peptide repertoire. Nature 486, 554-558. doi: 10.1038/nature11147

Jantararoungtong, T., Rerkpattanapipat, T., Prommas, S., Koomdee, N., Santon, S., Montri, C., et al. (2014). HLA-B*58:01 allele is strongly associated with allopurinol-induced severe cutaneous adverse reactions in a Thai population. Clin. Transl. Allergy 4(Suppl. 3), P120. doi: 10.1186/2045-7022-4-S3-P120

Jinam, T. A., Saitou, N., Edo, J., Mahmood, A., and Phipps, M. E. (2010). Molecular analysis of HLA Class I and Class II genes in four indigenous Malaysian populations. Tissue Antigens 75, 151-158. doi: 10.1111/j.1399-0039.2009.01417.x

Koomdee, N., Jantararoungtong, T., Rerkpattanapipat, T., Prommas, S., Santon, S., Chamnanphol, M., et al. (2014). HLA-B*15:02 genotype associated with hypersensitivity syndrome to Lamotrigine in Thai population. Clin. Transl. Allergy 4(Suppl. 3), P121. doi: 10.1186/2045-7022-4-S3-P121

Kulkantrakorn, K., Tassaneeyakul, W., Tiamkao, S., Jantararoungtong, T., Prabmechai, N., et al. (2012). HLA-B*1502 strongly predicts carbamazepineinduced Stevens-Johnson syndrome and toxic epidermal necrolysis in Thai patients with neuropathic pain. Pain Pract. 12, 202-208. doi: 10.1111/j.15332500.2011.00479.x

Kupatawintu, P., Pheancharoen, S., Srisuddee, A., Tanaka, H., Tadokoro, K., and Nathalang, O. (2010). HLA-A, -B, -DR haplotype frequencies in the Thai Stem Cell Donor Registry. Tissue Antigens 75, 730-736. doi: 10.1111/j.13990039.2010.01450.x

Li, H., Dai, Y., Huang, H., Li, L., Leng, S., Cheng, J., et al. (2007). HLA-B*1301 as a biomarker for genetic susceptibility to hypersensitivity dermatitis induced by trichloroethylene among workers in China. Environ. Health Perspect. 115, 1553-1556. doi: 10.1289/ehp.10325

Lin, L. C., Lai, P. C., Yang, S. F., and Yang, R. C. (2009). Oxcarbazepine-induced Stevens-Johnson syndrome: a case report. Kaohsiung J. Med. Sci. 25, 82-86. doi: 10.1016/S1607-551X(09)70045-2

Mallal, S., Phillips, E., Carosi, G., Molina, J. M., Workman, C., Tomazic, J., et al. (2008). HLA-B*5701 screening for hypersensitivity to abacavir. N.Engl. J. Med. 358, 568-579. doi: 10.1056/NEJMoa0706135

Man, C. B., Kwan, P., Baum, L., Yu, E., Lau, K. M., Cheng, A. S., et al. (2007). Association between HLA-B*1502 allele and antiepileptic drug-induced cutaneous reactions in Han Chinese. Epilepsia 48, 1015-1018. doi: 10.1111/j.15 28-1167.2007.01022.x

Middleton, D., Hawkins, B. R., Williams, F., Meenagh, A., Moscoso, J., Zamora, J., et al. (2004). HLA class I allele distribution of a Hong Kong Chinese population based on high-resolution PCR-SSOP typing. Tissue Antigens 63, 555-561. doi: 10.1111/j.0001-2815.2004.00234.x

Romphruk, A. V., Romphruk, A., Kongmaroeng, C., Klumkrathok, K., Paupairoj, C., and Leelayuwat, C. (2010). HLA class I and II alleles and haplotypes in ethnic Northeast Thais. Tissue Antigens 75, 701-711. doi: 10.1111/j.13990039.2010.01448.x

Saokaew, S., Tassaneeyakul, W., Maenthaisong, R., and Chaiyakunapruk, N. (2014). Cost-effectiveness analysis of HLA-B*5801 testing in preventing allopurinolinduced SJS/TEN in Thai population. PLoS ONE 9:e94294. doi: 10.1371/journal.pone.0094294

Sukasem, C., Ngamsamut, N., Rerkpattanapipat, T., Sinrachatanant, A., Chamkrachchangpada, B., Tan-kam, T., et al. (2014b). Association between HLA-B*1502 allele and aromatic antiepileptic drugs-induced cutaneous adverse drug reactions and the HLA-B*15:02 pharmacogenetics screening in autistic spectrum disorder. Clin. Transl. Allergy 4(Suppl. 3), P124. doi: 10.1186/2045-7022-4-S3-P124

Sukasem, C., Puangpetch, A., Medhasi, S., and Tassaneeyakul, W. (2014a). Pharmacogenomics of drug-induced hypersensitivity reactions: challenges, opportunities and clinical implementation. Asian Pac. J. Allergy Immunol. 32, 111-123.

Tangamornsuksan, W., Chaiyakunapruk, N., Somkrua, R., Lohitnavy, M., and Tassaneeyakul, W. (2013). Relationship between the HLA-B*1502 allele and carbamazepine-induced Stevens-Johnson syndrome and toxic epidermal necrolysis: a systematic review and meta-analysis. JAMA Dermatol. 149, 1025-1032. doi: 10.1001/jamadermatol.2013.4114

Tassaneeyakul, W., Jantararoungtong, T., Chen, P., Lin, P. Y., Tiamkao, S., Khunarkornsiri, U., et al. (2009). Strong association between HLA-B*5801 and allopurinol-induced Stevens-Johnson syndrome and toxic epidermal necrolysis in a Thai population. Pharmacogenet. Genomics 19, 704-709. doi: 10.1097/FPC.0b013e328330a3b8

Tassaneeyakul, W., Tiamkao, S., Jantararoungtong, T., Chen, P., Lin, S. Y., Chen, W. H., et al. (2010). Association between HLA-B* 1502 and carbamazepineinduced severe cutaneous adverse drug reactions in a Thai population. Epilepsia 51, 926-930. doi: 10.1111/j.1528-1167.2010.02533.x

Wangsomboonsiri, W., Mahasirimongkol, S., Chantarangsu, S., Kiertiburanakul, S., Charoenyingwattana, A., Komindr, S., et al. (2010). Association between HLA-B* 4001 and lipodystrophy among HIV-infected patients from Thailand who received a stavudine-containing antiretroviral regimen. Clin. Infect. Dis. 50, 597-604 doi: 10.1086/650003

Williams, F., Meenagh, A., Darke, C., Acosta, A., Daar, A. S., Gorodezky, C., et al. (2001). Analysis of the distribution of HLA-B alleles in populations from five continents. Hum. Immunol. 62, 645-650. doi: 10.1016/S0198-8859(01) 00247-6

Conflict of Interest Statement: The reviewer Wichittra Tassaneeyakul declares that, despite having collaborated with authors Apichaya Puangpetch and Chonlaphat Sukasem, the review process was handled objectively and no conflict of interest exists. The authors have no relevant affiliations or financial involvement with any organization or entity with a financial interest in or financial conflict with the subject matter or materials discussed in the manuscript.

Received: 30 October 2014; accepted: 30 December 2014; published online: 22 January 2015.

Citation: Puangpetch A, Koomdee N, Chamnanphol M, Jantararoungtong T, Santon S, Prommas S, Hongkaew Y and Sukasem C (2015) HLA-B allele and haplotype diversity among Thai patients identified by PCR-SSOP: evidence for high risk of drug-induced hypersensitivity. Front. Genet. 5:478. doi: 10.3389/fgene.2014.00478 This article was submitted to Pharmacogenetics and Pharmacogenomics, a section of the journal Frontiers in Genetics.

Copyright $\odot 2015$ Puangpetch, Koomdee, Chamnanphol, Jantararoungtong, Santon, Prommas, Hongkaew and Sukasem. This is an open-access article distributed under the terms of the Creative Commons Attribution License (CC BY). The use, distribution or reproduction in other forums is permitted, provided the original author(s) or licensor are credited and that the original publication in this journal is cited, in accordance with accepted academic practice. No use, distribution or reproduction is permitted which does not comply with these terms. 